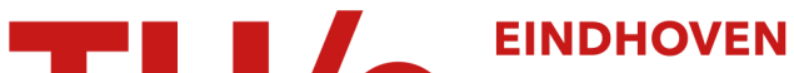 \\ UNIVERSITY OF \\ TECHNOLOGY
}

\section{Planning systems in the next century (I)}

Citation for published version (APA):

Euwe, M. J., \& Wortmann, J. C. (1997). Planning systems in the next century (I). Computers in Industry, 34(2), 233-237. https://doi.org/10.1016/S0166-3615\%2897\%2900058-4, https://doi.org/10.1016/S0166-3615(97)000584

DOI:

10.1016/S0166-3615\%2897\%2900058-4

10.1016/S0166-3615(97)00058-4

Document status and date:

Published: 01/01/1997

\section{Document Version:}

Publisher's PDF, also known as Version of Record (includes final page, issue and volume numbers)

\section{Please check the document version of this publication:}

-A submitted manuscript is the version of the article upon submission and before peer-review. There can be important differences between the submitted version and the official published version of record. People interested in the research are advised to contact the author for the final version of the publication, or visit the $\mathrm{DOI}$ to the publisher's website.

- The final author version and the galley proof are versions of the publication after peer review.

- The final published version features the final layout of the paper including the volume, issue and page numbers.

Link to publication

\section{General rights}

Copyright and moral rights for the publications made accessible in the public portal are retained by the authors and/or other copyright owners and it is a condition of accessing publications that users recognise and abide by the legal requirements associated with these rights.

- Users may download and print one copy of any publication from the public portal for the purpose of private study or research.

- You may not further distribute the material or use it for any profit-making activity or commercial gain

- You may freely distribute the URL identifying the publication in the public portal.

If the publication is distributed under the terms of Article $25 \mathrm{fa}$ of the Dutch Copyright Act, indicated by the "Taverne" license above, please follow below link for the End User Agreement:

www.tue.nl/taverne

Take down policy

If you believe that this document breaches copyright please contact us at:

openaccess@tue.nl

providing details and we will investigate your claim. 


\title{
Planning systems in the next century (I)
}

\author{
Mark J. Euwe a,b, * Hans Wortmann ${ }^{\text {a,b }}$ \\ aindhoven University of Technology, Faculty of Industrial Engineering and Management Science, P.O. Box 513, \\ $5600 \mathrm{MB}$ Eindhoven. Netherlands \\ b Andersen Consulting, Management Consultants, Amsterdam, Netherlands
}

\begin{abstract}
This document is the first part of two articles that present a vision on planning systems in the next century. It is mostly concerned with the medium- and long-term planning levels, whereas the second paper is much more focused on the short-term planning level, e.g., shopfloor control. First, a brief overview is given of problems that exist in current planning concepts and planning systems. The general statement is that current planning concepts and systems are often too simple in their modelling of the real world. This is illustrated using the example of Material Requirements Planning (MRP). The next section describes five 'vision statements' that have been setup to present a vision on future planning systems. These statements describe a number of aspects of planning systems and should be seen as high-level directions in future developments. The most important thought presented here is that a transition will take place from one centralized planning environment into an environment that contains multiple autonomous planning systems, where planning systems are able to cooperate with other planning systems based on defined protocols. Furthermore, the role of the human planner will focus much more on control instead of execution. The last section describes a number of barriers that must be overcome to realize the presented vision. (C) 1997 Elsevier Science B.V.
\end{abstract}

\section{Problems in current planning concepts and systems}

Although references to certain planning levels are not made for the remainder of this paper, we will consider the scope of our discussion to be the medium and long term planning levels. We will consider these planning levels to be the upper planning levels in the MRPII framework, i.e., Business Planning, Sales and Operations Planning, Master Production Scheduling, Material Requirements Planning (MRP) and Capacity Requirements Planning [1]. With reference to the framework of Bertrand et al. [2], this

\footnotetext{
* Corresponding author. E-mail: M.Euwe@tm.tue.nl,HWO@ tm.tue.nl. E-mail Andersen Consulting: Mark.J.Euwe@ac.com.
}

would be Master Planning and Logistical Coordination.

Whenever planners are asked about problems that they encounter in their daily practice, usually a diversity of answers is given, varying from a low level to a high level of detail. Responses could be varying from basics like:

"Why doesn't the system 'understand' that these goods can no longer be used in 2 months, because they will be expired?'"

to responses that focus on more higher level problems like:

"Why can't the system propose the use of a different supplier, when the leadtime is too short for our regular supplier?" 
"Why does the system tell me the same things everyday again, although I have read those messages yesterday and the day before yesterday?'

When taking one step backwards from these problems, it can be concluded that current manufacturing planning concepts and systems are often too simple in their model of the real world. A distinction is made between modelling the world's objects and their characteristics, and the modelling of the processes that act upon those objects. Models are by nature simplifications of reality. In planning systems, this means that certain aspects of reality are simply not considered (e.g., process flexibility), because these aspects have not been modelled. However, modelling objects and their characteristics is not enough. The data on objects should also be used in the 'right' manner. This relates to the way real-life planning processes are modelled in concepts and systems. Again, oversimplification may lead to lower planning results. Table 1 describes sevcral wellknown problems in terms of modelling errors.

No model of uncertainty, for instance, indicates that there is no information incorporated in the concept or system that indicates the extent in which quantities and dates might change in the future.

The remark 'No model of supplier and customer processes' expresses that the only thing we usually know about supplier and customer processes is a delivery date and a quantity.

No model of the planner indicates that generally there is no information available on state of mind of

Table 1

Problems in terms of modelling errors

\begin{tabular}{ll}
\hline Modelling of objects & Modelling of planning processes \\
\hline No model of: & - Lack of integration between planning \\
& levels \\
- flexibility & - Anxicty of planning \\
- uncertainty & - No iterative processing \\
- constraints on: & - No use of alternative plans \\
- capacity & - Only periodic planning runs \\
- people & - Little information sharing with suppliers \\
- tools & and customers \\
- storage areas, etc. & \\
- supplier processes & \\
- customer processes & \\
- planner & \\
\hline
\end{tabular}

the planner. For instance, which messages did the planner receive and should therefore not be given again?

\section{Examples of modelling errors in MRP}

To illustrate the statements in Section 1, we will discuss a number of examples of modelling problems within the area of MRP. MRP is regarded as a good example, since it is the most widespread planning concept and system in industry today. Please note that this list contains only a few examples. For a more detailed and complete overview see Ref. [3].

\subsection{Flexibility in lotsizes}

In reality 'fixed lotsizes' are not always fixed. Due to all kinds of good reasons, it may be decided to change the lotsize into a different (higher or lower) quantity. For instance, if there are not enough components for a full batch quantity, then it may be decided to start an order with a lower quantity than the lotsize. Since this lotsize flexibility has not been modelled in the MRP system, MRP always generates planned orders with the same fixed lotsize, regardless of consequences of missing components, 'dead' stock, etc.

\subsection{Product structures}

Reality shows a wide diversity of production processes, e.g., process industry, semiprocess, and discrete manufacturing. MRP has been originally set up for assembly-oriented production. This means that the model of the standard MRP product structure is focused on assembling components into subassemblies. Processes where a production step results in several subassemblies or endproducts are therefore not well supported.

\subsection{Capacity constraints}

Reality shows factories / companies with only limited resources. MRP 'assumes' that there is always enough resources available to realise a material planning. This is based on the assumption that capacity 
availability has already been checked when setting up the MPS. However, this was done using a Rough Cut Capacity Check, which can differ significantly from a Detailed Capacity Check, especially in the short term ${ }^{1}[4,5]$.

\subsection{Alternative plans}

In reality planners do have several scenarios that they consider when setting up a planning system. For instance, in case of capacity shortages there may be several alternatives, e.g., lotsplitting, subcontracting, overwork, etc. that can be applied to solve the problem. This characteristic of the planning process has not been modelled within MRP. Therefore, MRP generates only one plin.

\section{Future planning systems: 'vision' statements}

A lot of drawbacks of current planning systems can simply be explained by looking at the model that was used to build the planning concepts and systems. When setting up a vision on planning systems in the future, it would be a bit too easy to simply state that 'all these problems will be solved'. On the other hand it is not possible to supply a complete integrated vision that tackles all these problems, simply because solutions are not yet known for the majority of them.

Therefore, we will discuss a number of 'vision' statements, that discuss certain aspects of futurc planning systems. It should be noted that these statements are intended to stimulate discussion on this subject and should be seen as high-level directions of future developments. However, we believe that these directions provide better opportunities to handle the problems mentioned previously.

\subsection{Autonomous cooperative planning systems}

Autonomous cooperative planning systems are systems on different planning levels in the organiza-

\footnotetext{
${ }^{1}$ Note that in most MRP systems, data is available on capacity availability. However, this information is not used at all in the MRP algorithm.
}

tion that communicate by means of common planning protocols within and across company borders.

In the future, instead of having one central planning system, several autonomous planning systems will be in place within the organization. These planning systems are capable (within boundaries) to perform planning processes autonomously and communicate with other planning systems. Communication will be based on dedicated planning protocols, that contain standard messages like 'request material', 'request date change', 'request additional material', etc. This type of EDI-like communication will also allow communication across company borders, thereby integrating the companies' planning processes with the planning processes of suppliers and customers.

\subsection{Continuous planning systems}

This involves continuous (event-driven) planning and replanning on dedicated planning systems.

Currently, planning processes are often performed on a periodic basis on general-purpose systems. This always leads to situations where the plan is not up-to-date and no longer completely valid. In the future, (re)planning will take place immediately upon events that may influence the planning, e.g., entry of new customer orders, due date changes, machine breakdowns, excessive scrap, etc. During replanning, anxiety constraints will be taken into account, to minimize schedule disturbances. Besides this eventdriven planning, optimizing algorithms may constantly be searching for possibilities to improve upon the current schedule. This is all done on computer systems that are dedicated to the planning process.

\subsection{Planning toolkits}

Planning software based on modules from several suppliers are extended with planning toolkits that allow users to realise company specific planning requirements.

Currently, planning software can only be adapted to the needs of the company by modifying a number of built-in parameters. (e.g., SAP, Triton, etc.). In the future, planning systems will much more be constructed from standard modules (which may come 
from different suppliers), that can easily be modified using planning toolkits. These toolkits contain libraries of functions and procedures relevant for planning purposes. Furthermore, they will support the modelling of new objects. Examples of functions could be: (1) functions that calculate time-phased stock patterns; (2) functions that calculate lotsizes based on historical data; and (3) tools to define your own stock types. These tools may be uscd by the planner to adapt the planning concepts for specific materials or groups of material.

\subsection{Control vs. execution}

This involves highly automated planning systems that give better decision support to the planner, autonomously perform routine tasks and require human involvement on an exception basis.

Currently, planning systems do not really support the planner in case of problems. In fact, when it is getting difficult, support of the planning systems soon drops to zero, leaving the planner with the problems. In the future, planning systems will be much more robust in the sense that they will be able to investigate simple problems autonomously and propose alternative solutions to the planner. After comparing alternatives, the planner can then select an alternative that should be implemented. The next step is that the planner hands over responsibility to the planning system for solving certain well-defined problems. When the intelligence of the planning system increases, more and more situations can be handled by the planning system. This will enable the planner to concentrate on control tasks instead of execution tasks.

\subsection{Learning systems}

These involve systems with learning capabilities that are able to learn from previous experiences with other planning systems, and are able to elicit specific knowledge from the planner.

Currently, planning systems do not keep track of their environment, i.e., the human planner's state of mind is not modelled, nor is the 'behaviour' of other planning processes modelled. In the future, planning systems will contain models of the planners' state of mind and the knowledge that planners use to solve specific problems. Furthermore, learning capabilities will be incorporated to extend from this knowledgc. This will not only be done for human planners, but also for other planning systems. For instance, if the system that controls a specific machine communicates a breakdown to the scheduling system, then reaction time may depend on a historical analysis of breakdown handling in the past.

\section{Conclusion}

The 'vision' statements that have been presented can be seen as high-level directions for future developments. Barriers that have to be overcome to realize these directions will evolve in a number of areas. First, is the area of technology. The future will require massive processing power (against reasonable cost) to calculate all kinds of alternative schedules. Additional, more distributed and modular architectures require further improvements in distributed database technologies. With increasing data communication, the same holds true for communication technology.

Besides new technological developments, new developments are also required in the area of modelling. It seems that current modelling techniques are not always efficient enough to capture sufficient features of reality. More realistic models are a prerequisite to improve problem-solving capabilities of planning systems. This is also nearly related to the area of Artificial Intelligence (AI), where developments are needed to enlarge the scope and domains of AI applications. The same is applicable for the area of learning systems.

The last area that has to be dealt with is the need for future systems to have a more open architecture. The realization of standard software modules with defined protocols, which may be used across company borders, will require tremendous standardization efforts. The extent, to which current software suppliers are willing to cooperate in these efforts, is questionable.

\section{Acknowledgements}

The author wants to thank the participants of the CIMMOD/CIMDEV workshop 'Planning systems 
in the next century' for their remarks. The workshop was held in Lisbon, July '95 at the ASI'95 conference as an invited special session.

\section{References}

[1] D.V. Landvater, C.D. Gray, MRP II Standard System, Oliver Wight Limited Publications, 1989.

[2] J.W.M. Bertrand, J. Wijngaard, J.C. Wortmann, Production Control, Elsevier, Amsterdam, 1989.

[3] M. Euwe, Problemen en knelpunten bij het gebruik van MRP in de praktijk, EUT/BOK/71 Report, University of Technology Eindhoven, 1994.

[4] T. Vollmann, W.L. Berry, D.C. Whybark, Manufacturing Planning and Control Systems, Richard D. Irwin, 1992.

[5] J.C. Wortmann, M.J. Euwe, M. Taal, V.C.S. Wiers, A review of capacity planning techniques within standard software packages. Production Planning and Control, 7 (2) $1996117-$ 128.

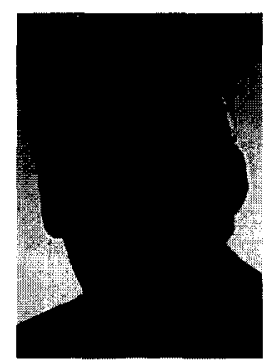

Mark J. Euwe holds a bachelors degree in computer science from the Venlo Institute for Technology and a masters degree in industrial engineering and management science from Eindhoven University of Technology (TUE). He is currently working as a project manager at Andersen Consulting and specializes in the fields of production control and logistics. Besides this he is doing research at TUE in the area of decentralized production planning and control.
Johan C. Wortmann studied industrial engineering and management science at Eindhoven University of Technology. He has been active in the development of information systems for production and inventory control since 1973 and wrote a doctoral thesis on the subject. He has been involved in a number of practical applications, both in component manufacturing and in assembly operations. He worked in the first half of 1985 as visiting professor at Rutgers University, New Jersey on databases. Dr. Wortmann is currently employed at Eindhoven University of Technology as professor of information systems for production management. 